\title{
A Computational Method To Characterize Framework Aluminum in Aluminosilicates $* *$
}

\author{
Elena García-Pérez, David Dubbeldam, Bei Liu, Berend Smit, and Sofía Calero*
}

Zeolites are aluminosilicates that are used in many applications involving catalysis, separation, and gas storage. ${ }^{[1-3]}$ Unlike the $\mathrm{Si} / \mathrm{Al}$ ratio of their framework, the location of the aluminum atoms is not well described. It has proved difficult to establish the local structure surrounding the aluminum sites by diffraction methods, since aluminum and silicon are very close in X-ray scattering power and thus XRD gives only the weighted average of the $\mathrm{Si}^{-} \mathrm{O}$ and $\mathrm{Al}-\mathrm{O}$ distances. Extended X-ray absorption fine structure (EXAFS) spectroscopy can be used to probe the local structure around aluminum in zeolites. This information is less accurate than the average from XRD, but the ability of EXAFS to probe the local structure around a selected element allows easy in situ measurements. ${ }^{[4]}$ Aluminum Xray adsorption near edge structure (XANES) spectroscopy can also be used to extract such information, although it does not yield interatomic distances. ${ }^{[5]}$ Several attempts have been made to probe structural variations by MAS-NMR spectroscopy ${ }^{[6-8]}$ but as soon as even small amounts of aluminum are present in the framework, the resolution is degraded and the spectra provide insufficient information about aluminum site preferences. ${ }^{[9]}$

These experimental challenges, combined with the importance of aluminum site distributions, have created a significant opportunity for molecular modeling, and important additional information about the local structure surrounding

[“] E. García-Pérez, Dr. S. Calero

Departamento Sistemas Físicos, Químicos y Naturales

Universidad Pablo de Olavide

Ctra. Utrera km. 1, 41013 Sevilla (Spain)

Fax: (+34) 954-349-814

E-mail: scaldia@upo.es

Dr. D. Dubbeldam

Chemical \& Biological Engineering Department

Northwestern University

Evanston, IL 60208 (USA)

B. Liu, Prof. B. Smit

Centre Européen de Calcul Atomique et Moléculaire (CECAM)

Ecole Normale Supérieure

46 allée d'Italie, 69007 Lyon (France)

Van't Hoff Institute for Molecular Sciences

University of Amsterdam

Nieuwe Achtergracht 166, 1018 WV Amsterdam (The Netherlands)

[**: This work was supported by the Spanish "Ministerio de Educación y Ciencia" (Ramón y Cajal Program and projects CTQ2004-00582/ BQU, CTQ2004-07730-C02-01/BQU, VEM2003 20574 C03 01), by the EC through the Marie Curie EXT project MEXT-CT-2005-023311, by the Dutch STW/CW program Separation Technology (700.56.655DPC.6243) and by the National Science Foundation (CTS-0507013). The authors wish to thank R. Krishna, J. M. van Baten, and R. Q. Snurr for useful discussions. aluminum sites has come from simulations. ${ }^{[7,10-13]}$ The aluminum distribution on the crystal level, as well as the distribution on the level of a single unit cell, remains a subject of debate. ${ }^{[14-20]}$ Herein, we present an alternative theoretical approach in which we identify those experimentally accessible properties that are crucially dependent on the aluminum distribution and associated cation distribution. Once these properties have been identified, we compute the most likely positions of aluminum in zeolites by matching simulation results with available experimental data. This crucially depends on the quality of the force field. Recently, two force fields were developed for sodium and protons in aluminosilicates that gave results that were not only qualitatively but also quantitatively in good agreement with experiments. ${ }^{[21,22]}$

We have performed molecular simulations to obtain the adsorption and diffusion properties of alkanes in a variety of zeolitic structures of industrial importance ${ }^{[23]}$ by varying the positions of the aluminum atoms. Figure 1 shows the unit cells
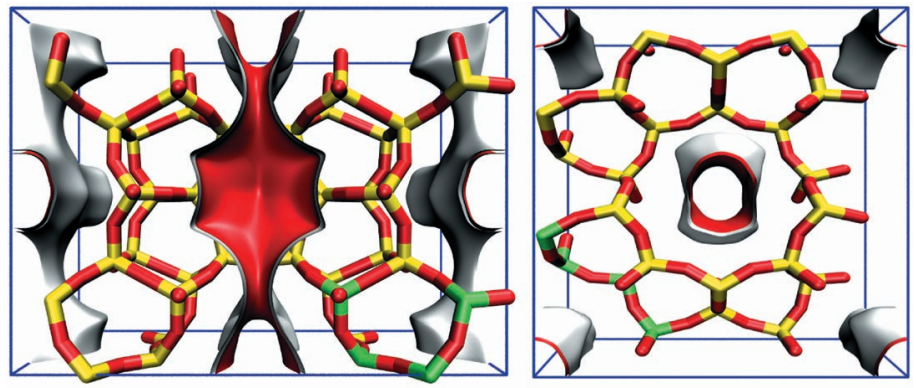

Figure 1. Unit cells of FER- (left) and TON-type (right) zeolites. O red, $\mathrm{Si}$ yellow, and the four crystallographically different $\mathrm{T}$-atoms green.

of FER and TON along with the four different crystallographic positions of the silicon and/or aluminum atoms (Tatoms). Although distributions over larger supercells may exist, ${ }^{[14]}$ our approach implicitly assumes a homogeneous aluminum distribution for the zeolite which is the same for each crystallographic unit cell. However, the method presented herein is in principle applicable to larger scale orderings. The best calibrated and optimized models for adsorption in these structures are the united-atom models, in which the $\mathrm{CH}_{x}$ groups of alkanes are represented as single, chargeless interaction centers with their own effective potentials. ${ }^{[2]}$ Recently, these models also gave quantitative agreement with neutron scattering experiments for collective and transport diffusivity of ethane in silicalite. ${ }^{[24]}$ 
The force field we used implicitly includes an "average" polarization in the parameterization by means of the polarization effect induced by the nonframework ions on the zeolite and on the alkanes. ${ }^{[21,22,25,26]}$ Adsorption and diffusion studies were performed by means of Monte Carlo (MC) and molecular dynamics (MD) simulations, respectively. Further details are given in reference [27]. Henry coefficients of linear alkanes were computed for all structures at a fixed $\mathrm{Si} / \mathrm{Al}$ ratio by varying the aluminum distribution and using $\mathrm{Na}^{+}$and $\mathrm{H}^{+}$ as nonframework ions. Our results show that adsorption properties of certain zeolitic structures are insensitive to the aluminum distribution, while for another class of structures the distribution does matter. Structures such as LTA, MFI, FAU, and MEL are included in the first group, while LTL, MOR, FER, and TON belong to the second class (for small alkanes). The first group was previously used to unambiguously parameterize our simulation method, ${ }^{[22,28]}$ and with the second group we can reverse-engineer the average aluminum distribution.

To discuss and illustrate the method to identify the aluminum positions, we carefully analyzed three zeolites for which experimental data are available for comparison and it is also feasible to consider all possible aluminum distributions per unit cell: $\mathrm{H}^{+}\left[\mathrm{AlSi}_{23} \mathrm{O}_{48}\right]-\mathrm{TON}$ and $\mathrm{H}^{+}\left[\mathrm{AlSi}_{35} \mathrm{O}_{72}\right]$-FER (with 4 possible aluminum distributions per unit cell shown in Figure 1), and $\mathrm{Na}_{8}^{+}\left[\mathrm{Al}_{8} \mathrm{Si}_{40} \mathrm{O}_{96}\right]$-MOR (with 16 possible aluminum distributions per unit cell).

The adsorption of alkanes in Na-MOR is strongly influenced by the aluminum distribution (Figure 2). Adsorption isotherms were calculated at $293 \mathrm{~K}$ for the 16 structures and compared with available experimental data ${ }^{[29]}$ (Figure 2a). Detailed adsorption behavior at low pressures is shown in Figure 2b, where Henry coefficients are computed
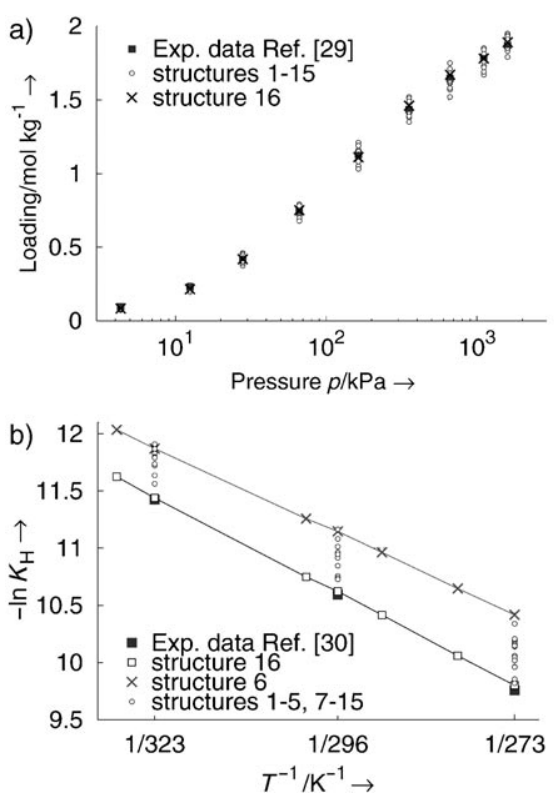

Figure 2. Adsorption of methane in $\mathrm{Na}_{8}^{+}\left[\mathrm{Al}_{8} \mathrm{Si}_{40} \mathrm{O}_{96}\right]-\mathrm{MOR}$ obtained by molecular simulations in comparison with experimental data. ${ }^{[2,30]}$ a) Adsorption isotherms at $293 \mathrm{~K}$. b) Henry coefficients $K_{\mathrm{H}}\left[\mathrm{mol} \mathrm{kg}^{-1} \mathrm{~Pa}^{-1}\right]$ as a function of temperature. at several temperatures. Methane shows the highest adsorption in structure 16 (Al atoms replace $\mathrm{Si} 4, \mathrm{Si} 18, \mathrm{Si} 31, \mathrm{Si} 42$, Si80, Si93, Si105, and Si115), and the lowest for structure 6 (Al atoms replace Si3, Si18, Si32, Si42, Si79, Si93, Si106, and Si115). The agreement with experimental values ${ }^{[30]}$ is remarkable for structure 16. In this structure the eight $\mathrm{Al}$ atoms are located in the 4-rings, in complete conformity with the suggested preferential sites of aluminum provided by previous crystallographic, experimental, and theoretical work. $^{[16,19,31-34]}$

The method is transferable to other protonated aluminosilicate structures, as shown in Figures 3 and 4 for H-FERand H-TON-type zeolites, respectively. Simulations were

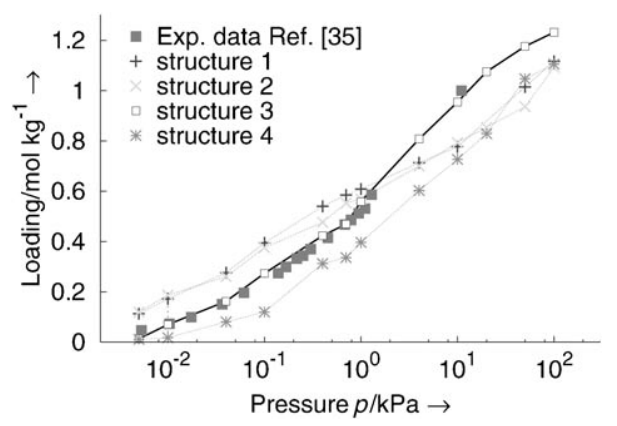

Figure 3. Adsorption isotherms of pentane in $\mathrm{H}^{+}\left[\mathrm{AISi}_{35} \mathrm{O}_{72}\right]-\mathrm{FER}$ at $333 \mathrm{~K}$ obtained by molecular simulations and compared with experimental data. ${ }^{[35]}$ Simulations were performed with 16 unit cells. The structure numbering is independent from that in Figure 2.

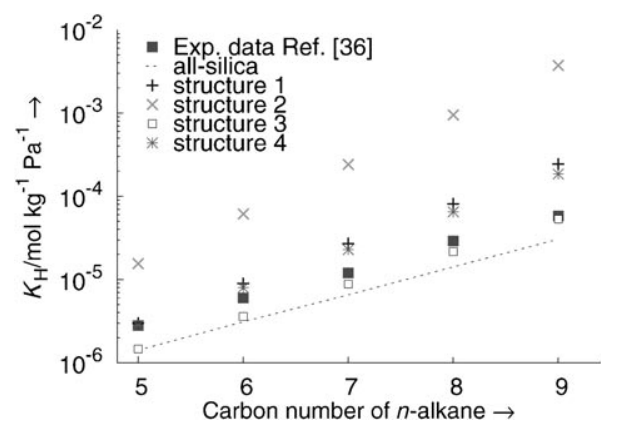

Figure 4. Calculated Henry coefficients as a function of the carbon number for the adsorption of linear alkanes-pentane, hexane, heptane, octane, and nonane-in $\mathrm{H}^{+}\left[\mathrm{AlSi}_{23} \mathrm{O}_{48}\right]$-TON at $548 \mathrm{~K}$ compared with experimental data. ${ }^{\left[{ }^{36]}\right.}$ Simulations were performed with 20 unit cells. The structure numbering is identical to that in Figure 3.

performed for propane, butane, pentane, hexane, heptane, octane, and nonane for all feasible protonated structures (four possible Al positions for each zeolite). Structures with aluminum substitutions at $\mathrm{Si} 1, \mathrm{Si} 2, \mathrm{Si} 3$, and $\mathrm{Si} 4$ are labeled as structures 1, 2, 3, and 4, respectively. Direct comparison with the experimental values ${ }^{[35,36]}$ predicts that most of the aluminum atoms in the experimental zeolite sample substituted $\mathrm{Si} 3$ in H-FER structures, and $\mathrm{Si} 3$ and $\mathrm{Si} 4$ in H-TON structures.

Diffusion coefficients of methane and ethane in TON and FER structures were computed (Table 1). Diffusion of 
Table 1: Diffusion coefficients $\left[10^{-8} \mathrm{~m}^{2} \mathrm{~s}\right]$ of linear alkanes in $\mathrm{H}^{+}\left[\mathrm{AlSi}_{23} \mathrm{O}_{48}\right]-$ TON and $\mathrm{H}^{+}\left[\mathrm{AlSi}_{35} \mathrm{O}_{72}\right]-\mathrm{FER}$ at $548 \mathrm{~K}$.

\begin{tabular}{lllll}
\hline & \multicolumn{2}{c}{ H-TON } & \multicolumn{2}{c}{ H-FER } \\
& Methane & Ethane & Methane & Ethane \\
\hline pure silica & $0.74 \pm 0.01$ & $0.49 \pm 0.01$ & $2.2 \pm 0.1$ & $0.89 \pm 0.03$ \\
structure 1 & $0.43 \pm 0.04$ & $0.29 \pm 0.02$ & $2.6 \pm 0.1$ & $1.04 \pm 0.05$ \\
structure 2 & $0.67 \pm 0.03$ & $0.47 \pm 0.04$ & $1.5 \pm 0.1$ & $0.59 \pm 0.04$ \\
structure 3 & $0.26 \pm 0.01$ & $0.22 \pm 0.01$ & $1.1 \pm 0.1$ & $0.31 \pm 0.04$ \\
structure 4 & $0.39 \pm 0.03$ & $0.29 \pm 0.04$ & $1.3 \pm 0.1$ & $0.39 \pm 0.05$ \\
\hline
\end{tabular}

methane and ethane is faster in FER structures than in TON structures. According to our results both types of structure provide lower diffusivity when $\mathrm{Si} 3$ and $\mathrm{Si} 4$ are substituted and the highest when Si2 and Si1 are substituted. Substitutions in $\mathrm{Si} 2$ and Si1 provide similar diffusivity to pure-silica TON and FER, respectively. We note that the idea of reverse-engineering aluminum positions is not restricted to adsorption properties alone but, when experimental data become available, could also be applied to diffusion or other dynamic information.

The field of molecular simulation is rapidly expanding, and future advances in force fields could lead to similar approaches for other systems. The presented relation between adsorption/diffusion properties and aluminum distributions can be exploited for designing more-efficient industrial adsorbents. It should be possible, in the longer term, to use these data to more clearly delineate any relationships between the aluminum locations and the catalytic activities and selectivities of aluminosilicates.

Received: August 2, 2006

Revised: September 25, 2006

Published online: November 10, 2006

Keywords: adsorption - alkanes · aluminum .

computer chemistry $\cdot$ zeolites

[1] M. Guisnet, J.-P. Gilson, Zeolites for Cleaner Technologies, Vol. 3, Imperial College Press, New York, 2002.

[2] R. Krishna, B. Smit, S. Calero, Chem. Soc. Rev. 2002, 31, 185.

[3] A. Corma, H. Garcia, Chem. Commun. 2004, 1443.

[4] J. A. van Bokhoven, H. Sambe, D. E. Ramaker, D. C. Koningsberger, J. Phys. Chem. B 1999, 103, 7557.

[5] J. A. van Bokhoven, D. C. Koningsberger, P. Kunkeler, H. van Bekkum, J. Catal. 2002, 211, 540.

[6] G. Engelhardt, D. Michel, High Resolution Solid State NMR of Silicates and Zeolites, Wiley, New York, 1987.

[7] J. O. Ehresmann, W. Wang, B. Herreros, D. P. Luigi, T. N. Venkatraman, W. G. Song, J. B. Nicholas, J. F. Haw, J. Am. Chem. Soc. 2002, 124, 10868.
[8] C. A. Fyfe, J. M. Thomas, J. Klinowski, G. C. Gobbi, Angew. Chem. 1983, 95, 257; Angew. Chem. Int. Ed. Engl. 1983, 22, 259.

[9] R. W. Joyner, A. D. Smith, M. Stockenhuber, M. W. E. van den Berg, Phys. Chem. Chem. Phys. 2004, 6, 5435.

[10] M. Brandle, J. Sauer, R. Dovesi, N. M. Harrison, J. Chem. Phys. 1998, 109, 10379.

[11] U. Eichler, M. Brandle, J. Sauer, J. Phys. Chem. B 1997, 101, 10035.

[12] E. Beerdsen, B. Smit, S. Calero, J. Phys. Chem. B 2002, 106, 10659.

[13] E. Beerdsen, D. Dubbeldam, B. Smit, T. J. H. Vlugt, S. Calero, J. Phys. Chem. B 2003, 107, 12088.

[14] T. Takaishi, M. Kato, K. Itabashi, Zeolites 1995, 15, 21.

[15] B. K. Peterson, J. Phys. Chem. B 1999, 103, 3145.

[16] T. I. Koranyi, J. B. Nagy, J. Phys. Chem. B 2005, 109, 15791.

[17] C. P. Herrero, L. Utrera, R. Ramirez, Phys. Rev. B 1992, 46, 787.

[18] A. J. Vega, J. Phys. Chem. 1996, 100, 833.

[19] P. Bodart, J. B. Nagy, G. Debras, Z. Gabelica, P. A. Jacobs, J. Phys. Chem. 1986, 90, 5183.

[20] D. T. Ding, B. H. Li, P. C. Sun, Q. H. Jin, J. Z. Wang, Zeolites 1995, $15,569$.

[21] S. Calero, M. D. Lobato, E. Garcia-Perez, J. A. Mejias, S. Lago, T. J. H. Vlugt, T. L. M. Maesen, B. Smit, D. Dubbeldam, J. Phys. Chem. B 2006, 110, 5838.

[22] S. Calero, D. Dubbeldam, R. Krishna, B. Smit, T. J. H. Vlugt, J. F. M. Denayer, J. A. Martens, T. L. M. Maesen, J. Am. Chem. Soc. 2004, 126, 11377.

[23] C. Baerlocher, W. M. Meier, D. H. Olson, Atlas of Zeolite Structure Types, 5th ed., Elsevier, London, 2001.

[24] C. Shang-Shan, H. Jobic, M. Plazanet, D. S. Sholl, Chem. Phys. Lett. 2005, 408, 157.

[25] D. Dubbeldam, S. Calero, T. J. H. Vlugt, R. Krishna, T. L. M. Maesen, E. Beerdsen, B. Smit, Phys. Rev. Lett. 2004, 93.

[26] E. Jaramillo, S. M. Auerbach, J. Phys. Chem. B 1999, 103, 9589.

[27] D. Dubbeldam, E. Beerdsen, T. J. H. Vlugt, B. Smit, J. Chem. Phys. 2005, 122.

[28] E. Garcia-Pérez, I. M. Torrens, S. Lago, D. Dubbeldam, T. J. H. Vlugt, T. L. M. Maesen, B. Smit, R. Krishna, S. Calero, Appl. Surf. Sci. 2005, 252, 716.

[29] J. A. Delgado, M. A. Uguina, J. M. Gomez, Stud. Surf. Sci. Catal. 2005, $158 A$ and $B, 1065$.

[30] M. D. Macedonia, D. D. Moore, E. J. Maginn, Langmuir 2000, $16,3823$.

[31] J. L. Schelenker, J. J. Pluth, J. V. Smith, Mater. Res. Bull. 1968, 3 , 169.

[32] W. M. Meier, V. Z. Gramlich, Kristallogr. 1978, 147, 329.

[33] E. G. Derouane, J. J. Fripiat, Proceedings of the 6th International Zeolite Conference, Reno, 1984, p. 717.

[34] G. Debras, J. B. Nagy, Z. Gabelica, P. Bodart, P. A. Jacobs, Chem. Lett. 1983, 199.

[35] F. Eder, M. Stockenhuber, J. A. Lercher, J. Phys. Chem. B 1997, $101,5414$.

[36] R. A. Ocakoglu, J. F. M. Denayer, G. B. Marin, J. A. Martens, G. V. Baron, J. Phys. Chem. B 2003, 107, 398. 